\title{
Exploring contemporary patterns of cultural consumption: offline and online film watching in the UK [version 1; peer
}

\section{review: 2 approved]}

\author{
Matthew Hanchard (D1), Peter Merrington11, Bridgette Wessels¹, Simeon Yates² \\ ${ }^{1}$ School of Social and Political Sciences, University of Glasgow, Glasgow, G12 8RT, United Kingdom \\ ${ }^{2}$ Department of Communication and Media, University of Liverpool, Liverpool, L69 7ZG, United Kingdom
}

\author{
V1 First published: 30 Oct 2019, 1:16 \\ https://doi.org/10.35241/emeraldopenres.13196.1 \\ Latest published: 30 Oct 2019, 1:16 \\ https://doi.org/10.35241/emeraldopenres.13196.1
}

\begin{abstract}
This paper focuses on patterns of film consumption within cultural consumption more broadly to assess trends in consumerism such as eclectic consumption, individualised consumption and omnivorous/univorous consumption and whether economic background and status feature in shaping cultural consumption. We focus on film because it is widely consumed, online and offline, and has many genres that vary in terms of perceived artistic and entertainment value. In broad terms, film is differentiated between mainstream commercially driven film such as Hollywood blockbusters, middlebrow 'feel good' movies and independent arthouse and foreign language film. Our empirical statistical analysis shows that film consumers watch a wide range of genres. However, films deemed to hold artistic value such as arthouse and foreign language feature as part of broad and wide-ranging pattern of consumption of film that attracts its own dedicated consumers. Though we found that social and economic factors remain predictors of cultural consumption the overall picture is more complex than a simple direct correspondence and perceptions of other cultural forms also play a role. Those likely to consume arthouse and foreign language film consume other film genres and other cultural forms genres and those who 'prefer' arthouse and foreign language film have slightly more constrained socio-economic characteristics. Overall, we find that economic and cultural factors such income, education, and wider consumption of culture are significant in patterns of film consumption.
\end{abstract}

Keywords

Film, cultural consumption, consumers

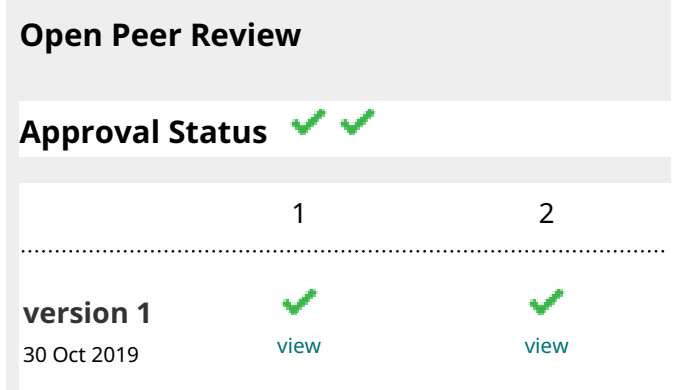

1. Abureza M. Muzareba ID, University of Dhaka, Dhaka, Bangladesh

2. Anna Kime (iD), Birds Eye View Films,

Sheffield, United Kingdom

Any reports and responses or comments on the article can be found at the end of the article. 
This article is included in the Fairer Society

gateway.

Corresponding author: Matthew Hanchard (matthew.hanchard@glasgow.ac.uk)

Author roles: Hanchard M: Writing - Original Draft Preparation, Writing - Review \& Editing; Merrington P: Writing - Original Draft Preparation, Writing - Review \& Editing; Wessels B: Conceptualization, Funding Acquisition, Writing - Original Draft Preparation, Writing - Review \& Editing; Yates S: Conceptualization, Data Curation, Formal Analysis, Methodology, Visualization, Writing - Original Draft Preparation, Writing - Review \& Editing

Competing interests: No competing interests were disclosed.

Grant information: The data and analysis presented in this paper are part of the Arts and Humanities Research Council (AHRC) funded project 'Beyond the Multiplex: Audiences for specialised film in English regions' [AH/FP005780/2F1]. Details of the project are available at: https://gtr.ukri.org/projects?ref=AH\%2FP005780\%.

The funders had no role in study design, data collection and analysis, decision to publish, or preparation of the manuscript.

Copyright: @ 2019 Hanchard $\mathrm{M}$ et al. This is an open access article distributed under the terms of the Creative Commons Attribution License, which permits unrestricted use, distribution, and reproduction in any medium, provided the original work is properly cited.

How to cite this article: Hanchard M, Merrington $P$, Wessels $B$ and Yates S. Exploring contemporary patterns of cultural consumption: offline and online film watching in the UK [version 1; peer review: 2 approved] Emerald Open Research $2019,1: 16$ https://doi.org/10.35241/emeraldopenres.13196.1

First published: 30 Oct 2019, 1:16 https://doi.org/10.35241/emeraldopenres.13196.1 


\section{Introduction}

This paper focuses on patterns of film consumption within cultural consumption in the UK. The paper first examines how patterns of film consumption can be informed by debates around cultural consumption more broadly. In particular whether consumerism is now individualised, eclectic or whether economic background and status still feature in shaping cultural consumption. We focus on film because it is widely consumed and has many genres that vary in terms of perceived artistic and entertainment value. As such film provides a window into these potential consumer trends within one cultural form. The paper examines whether consumers of particular film genres form distinct latent classes of consumers, and if so what those patterns of consumption are. Although, there is some evidence to suggest that patterns of consumptions are changing (Friedman et al., 2015), there is limited systematic empirical analysis of patterns of consumption within cultural forms. To this end we undertake empirical statistical analysis to assess film preference and consumption in relation to both social factors (such as income, age, gender, education, and location of residence) as well as perceptions of a wider range of cultural forms. We primarily apply latent class analysis (LCA) and binomial logistic regression to two data sets: (a) the UK government Department of Culture, Media and Sports (DCMS) 'Taking Part' survey 2016/2017 (DCMS, 2017); and (b) the British Film Institute (BFI) 'Opening Our Eyes' survey (Northern Alliance and Ipsos MediaCT, 2011). This work forms the first step as part of a major study of film consumption (Beyond the Multiplex: Audiences for Specialised Film in English Regions"1 ${ }^{1}$. The analysis presented here forms the baseline we are using to inform deeper analysis of film consumption through interviews, focus groups and longitudinal survey work.

The paper first considers film consumption within the wider context of theories of cultural consumption. It discusses current debates about 'eclectic' consumption, social homological approaches to consumption and theories of individualised consumption. Second, the paper outlines debates about the relative influences of social stratification such as economic capital, status and individual choice in consumerism. Third, the paper outlines methods and analysis before presenting and discussing latent class models of film genre preferences and film genres viewed using the DCMS and BFI data. Membership of these classes, in particular the groups that consume arthouse and foreign language film are then modelled using binomial logistic regression. Finally, we discuss consumer attitudes to and consumption of different film genres in relation to theories of exploring the extent to which social, economic and cultural factors correspond with particular patterns.

${ }^{1}$ Beyond the Multiplex: Audiences for Specialised Film in English Regions is an AHRC funded project (grant: AH/P005780/1) conducted by Bridgette Wessels, David Forrest, Andrew Higson, Mike Pidd, Matthew Hanchard, Peter Merrington, Kathy Rogers, Roderik Smiths, and Nathan Townsend.

\section{Film and consumption}

One of the purported characteristics of contemporary cultural consumption is that consumers create eclectic patterns of cultural consumption (Friedman et al., 2015) by mixing popular and high culture (DiMaggio \& Mukhtar, 2004), or lowbrow middlebrow and highbrow culture (c.f. Gans, 1999). A trend towards more individual consumption potentially raises questions about the relationship amongst and between social stratification and individual choice in shaping overall patterns of consumption.

The characteristics of film enable analysis to address these questions and variations within one cultural form. Film attracts a wide range of audiences and is one of the main cultural activities that most people engage in (Northern Alliance and Ipsos MediaCT, 2011). Film is both commercially and artistically driven, has both popular and artistic aesthetics, and has a differentiated internal market of large-scale, big-budget blockbusters, small-scale, director-led, art-house films, and feel-good, middlebrow films (Durgnat, 1971; Grixti, 2009; Higson, no date). For many people film is accessible via television, online services and cinemas, and its genres offer choices that serve a variety of consumer tastes. Although genres are fluid and open to a range of definitions (Chandler, 1997), consumer choices may involve some distinction between genres, for example between rom-com and sci-fi within popular genres, as well as arthouse and foreign language film (Jones, 2015).

The consumption of film, however, is under-researched in the main sociological approaches to cultural consumption. For example, although Bennett et al. (2009) cover a wide range of consumption, film is subsumed into the moving image more widely without making a distinction between the media it is delivered through such as television or cinema. Austin (2016) notes that Bourdieu did not write much about screen cultures and even less about cinema. Recent Film Studies research draws on Bourdieu to address consumption and taste in Indie and Art cinema (Austin, 2016). However, Austin (2016) and his contributors use case studies rather than undertake comparable statistical data analyses to patterns of taste as found in Bourdieu's own work, which makes direct comparison with Bourdieu difficult.

Chan \& Goldthorpe's (2010) work is one of the few studies of the consumption of cinema in relation to sociological debates of cultural consumption. They considered film as well as music, theatre, dance, and the visual arts in a broad analysis of cultural consumption rather than a direct focus on film. Other theorists, such as Bauman (2007), focus theoretically on macro level, meso level and micro levels of consumption, with less attention paid to specific cultural forms. In the majority of these studies questions of consumption explored among or between cultural forms (film versus opera) and not among and between the types within the cultural form (e.g. film genres). As we note above film is one format where there is 
considerable genre variation with in the format itself. Therefore, a focus on film enables analysis to include a range of artistic and entertainment value in the patterning of consumption.

\section{Cultural consumption: social stratification and choice}

Provision of culture has expanded the UK over the past few decades (The Warwick Commission, 2015; UK Govt, 2018). This encompasses music, television, theatre, literature, newspapers, art galleries and museums, sport, videogames, restaurants, pubs and clubs as well as film. Within this variety, there are potential shifts between artistic and entertainment values of cultural forms that may shape consumption patterns through changing forms of taste and distinction (Friedman et al., 2015). Taste and cartographies of taste change in relation to new patterns of consumption and the composition of the market (Hebdige, 1982). As Hebdige (1982) argues, individuals and groups interpret and use cultural resources in creative ways, which may express changing tastes.

If consumers are selecting what to consume in a changing market of culture, it raises questions about what guides those decisions. This raises the question about how people 'learn to consume' (Veblen, 1975). For Bourdieu (1984) this requires embodied and institutional cultural capital, gained through education and class habitus with the taste of the highly educated being considered more legitimate. Taste is not necessarily equated with money rather there is a struggle for distinction through taste. Likewise, Weberian scholars see taste as an expression of status and as something learned. In Bourdieusian, and Weberian approaches taste is an objective and legitimate feature that aids the production and reproduction of hierarchies of social distinction. There are, however, limitations to these types of approaches because being relational they cannot address easily address change in consumption across cultural and national contexts (Lamont \& Lareau, 1988).

A hierarchical view of taste and consumption is also being challenged in work that argues that there has been a (perceived) flattening and pluralisation of consumer culture. These arguments are characterised through ideas about 'ordinary and connected' consumption rather than high culture, popular culture or identity consumerism (Friedman et al., 2015). The appearance of an egalitarian consumer ethic, is however open to debate, because there may be new forms of distinction embedded within it (Friedman et al., 2015). Friedman et al. (2015) argue explanations need to go beyond a highbrow model or the under theorised notion of 'omnivore' consumption (Peterson \& Simkus, 1992) to consider new ways of making distinction within cultural consumption.

This debate around cultural consumption focuses on the relative influence of stratification and individual free choice in shaping who consumes what, and why. One approach argues that there is a 'homology' in which what people consume arises from the linked aspects of social stratification and cultural stratification (Bourdieu, 1984; Weber, 1968). Another approach, 'individualisation' denies any link between class, status and consumption because in economically advanced societies, differences in taste and consumption are losing their grounding in social stratification Bauman (1998); Bauman (2001).

In working with Bourdieu's (1984) concepts as a framework there is a strong link between social, economic and cultural capital and types of cultural consumption. Those undertaking Weberian approaches argue that status mediates a homology between class and consumption (Chan \& Goldthorpe, 2007a; Chan \& Goldthorpe, 2007b; Weber, 1968). Although both Bourdieu (1984) and Weber (1968) argue that the status order is significant in shaping consumerism, they disagree about the characteristics of the relationship between class, status and type of consumption. Weber (1968) argues that class and status are distinctive and not strongly determined by each other whereas Bourdieu (1984) argues that status or his terms 'symbolic capital' is shaped by economic capital, mediated by social capital and cultural capital. Whereas Bauman (1998); Bauman (2001) takes an individualising perspective arguing that individuals' construct 'selves' through consumption practices, which shifts the focus from 'habitus to freedom' (Warde, 1997, p. 8) in consumer choices. In some individualisation approaches, gender and ethnicity may feature in consumer choices (Beck, 1992; Giddens, 1991).

There are limitations to these positions, one of which is that they miss the point that with an expansion of cultural consumption, new patterns of consumption, based on variety rather than specific forms, may develop. Peterson \& Simkus (1992) argue that cultural stratification maps onto social stratification in two different ways: (a) those in higher social strata consume a variety of culture across high, middle and lowbrow culture, which they call 'omnivores'; (b) those in lower socio-economic groups do not consume such a variety of culture, which they call 'univores'. Although, working from a Weberian perspective, Chan \& Goldthorpe (2010) also found that there is a patterning of consumption that does not fit either homological approaches or individualisation approaches. They found three types of consumers, 'omnivores', 'paucivores' and 'inactives': omnivores consume a greater variety of culture; 'paucivores' a limited set; and 'inactives' are non-consumers. They argue that there is a degree of stratification, influenced by education that shapes their consumption. However, Hanquinet (2013) addresses and seeks to engage with some of the emerging complexities of cultural class analysis (e.g. Le Roux et al., 2008). She finds diversity in cultural appreciation in that consumers can be 'omnivorous' when it comes to music, for example, but are a 'univore' in another cultural area such as reading. This, Hanquinet (2013) argues, results in a bricolage of consumer preferences. This generates a focus on what consumers select and configure in their cultural consumption and opens the possibility of cultural influences in consumerism that include stratification and status, whilst recognising choice.

To address the above debates about whether economic capital and status feature in shaping cultural consumption or if there is a trend towards 'eclectic' consumption we first consider the positioning of film in relation to other forms of cultural 
consumption. Second, we consider whether of film genres (categorised by BFI survey) cluster as forms in and of themselves or in terms of individual consumption. Here we address whether it is possible to identify a group of film viewers who consume a wide range of genres (an omnivore pattern of consumption) and how this group relates to the specific group who state a preference for arthouse and foreign language film. We are taking this to mean a preference for film with higher artistic rather than entertainment value to this group. Third, we are concerned with the relative importance of consumers' perceptions of a range of cultural forms, socio-economic background and status in predicting preferences and attendance/viewing for general 'omnivore' consumers and arthouse and foreign language film consumers.

We developed an analytical framework to understand and question trends in consumption such as eclectic consumption, greater individualisation of consumption and/or changing patterns of omnivore/univore consumption. The framework is guided by observations by Savage et al. (2013) and Bennett et al. (2009) that age and gender as well as economic and cultural capital may feature in consumption. We draw on Hanquinet (2013) to address cultural appreciation in terms of the artistic and entertainment values of film as well as Savage et al.'s (2018) focus on urban life. We assess Bourdieusian approaches by considering economic and cultural capital and its mediation through habitus and Weberian approaches to status through education and wider engagement in cultural engagement. Our analyses focus on data that measure or may be proxies for:

- Economic capital such as income.

- Cultural capital or status such as education.

- Proxies for aspects of identity such as age and gender.

- Location such as urban, suburban, and village/rural.

- Proxies for cultural appreciation to assess consumer driven taste rather than externally dictated taste and cultural hierarchies.

In order to assess taste, we deconstruct it as: (a) 'preferences' to generate information about what people like; (b) 'attendance' to provide insights into what consumers' actually do; and (c) 'perceptions' that yield insights into the value and experience of particular cultural forms. By combining these, we gain insights into the ways that taste forms through consumption rather than through a dominant aesthetic (Hanquinet et al., 2014). These may be, as Bourdieu (1984) would argue, preferences and perceptions embedded within dispositions. By modelling preference and attendance/viewing against perceptions and proxy variables for social, economic and cultural capital, we can gain understanding about how a mix of socio-cultural variables feature in a potentially eclectic consumer environment. Our analytical framework enables us to address Chan \& Goldthorpe's (2010) argument that cultural consumption should be studied as directly as possible and must include not only include what people say their preferences and perceptions are, but also what they do.

\section{Research methods}

To address how film consumption clusters within cultural forms raises some analytic challenges. Many cultural activities and preferences take place and are measured in a binary fashion; people attend cultural activities, or they do not, people like or they do not like certain films, they do or do not have certain perceptions of cultural forms. In terms of preferences, consumers are more likely to have strong opinions about what they like or do not like in terms of cultural consumption leading to binomial distributions of data. As a result, most measures in data sets remain binary (do or do not attend, like or dislike) or short-range ordinal measures. A second problem arises as many measures of cultural preferences and behaviour may be highly inter-correlated and data sets may suffer from 'multicollinearity' as preferences and activities are not mutually exclusive sets. As a result of this data reduction methods (such as factor analysis) that help to simplify analysis are poorly suited to such data.

To deal with predominantly categorical nature of the available data we have used Latent Class Analysis (LCA) as a route to data reduction. LCA is a subset of structural equation modelling, used to find groups or subtypes of cases in multivariate categorical data. A latent class is distinguished by a pattern of conditional probabilities that indicate the chance that each variable will take on certain values. LCA therefore looks to generate a set of 'classes' that best predict the probability that categorical measures such as 'yes/no' or 'once/twice/more appear together. LCA can then assign cases to groups (latent classes) according to those probabilities. In this sense LCA is analogous to factor analysis where latent classes have a similar role to factors - though cases and variables (not just variables) are allocated to classes. LCA can therefore be viewed as identifying the underlying (latent) groups of people (classes) with statistically similar results. Importantly, unlike other alternative methods such as the majority of cluster analyses, LCA provides overt criteria for selecting the optimum number of classes. We have used LCA to allocate respondents to latent classes across three measures:

1. Actual consumption and attendance (which forms people do see).

2. Film consumption by type (across all media).

3. Film genre preferences (what people say they like).

While the first two measures cover what people do, the third is experiential covering a broad range of expressions of preference. To categorise this complexity in a way that was meaningful for analysis, we differentiated between negative expressions (e.g. the film was 'boring') and positive ones (e.g. good). The allowed us to generate an ordinal measure which we then used to simplify the analysis by calculating a score for each cultural activity for each respondent. For example, negative expressions (e.g.) were scored as -1 while positive expressions were scored as +1 . From this, we created an then use the binVariable of the R package RcmdrMisc (version 2.5.1) to generate an ordinal measure. To do this, it binned the expressions into 
one of four possible categories using k-means clustering, marking ach as either as: 'Negative', 'Limited', 'Positive', or 'Very positive'. We then used these measures to compare perceptions of the 15 cultural activities $n$ the DCMS data with the film genre preference latent classes generated via a $\chi 2$ test for independence.

\section{Information about the data sets we use}

The DCMS's (2017) 'Taking Part' survey is a one year of a longitudinal face-to-face household survey of adults who are aged 16 and over ${ }^{2}$ that has run since 2005. We have used the adult data set in this analysis. The survey's main objective is to provide a central, reliable evidence source of data to analyse cultural, sports and digital engagement, providing a clear picture of why people do or do not engage in various cultural activities. The survey collects data on engagement in the arts, museums and galleries, archives, libraries, heritage and sport. It includes information on frequency of participation, reasons for participating, barriers to participation and attitudes to cultural sectors, and it gathers information on demographics (e.g. age, education, income and socio-economic status). 'Taking Part' is designed to yield a representative sample of 10,000 adults aged 16+ who are normally resident in England. The data collected in 2016-2017 sample $(\mathrm{N}=10,171)$ is a mixed sample, evenly divided between fresh sample cases and re-interview cases (DCMS, 2017). We used this dataset to model the latent classes of general arts and cultural attendance.

The second and main dataset for this paper is the BFI's 'Opening Our Eyes' study (Hanchard, 2019; Northern Alliance and Ipsos MediaCT, 2011). This had a mixed methods research design, composed of qualitative paired interviews, a survey and case studies. We have solely drawn on the publicly-available survey data which comprises 2,036 online self-completion questionnaires. The sample is representative of 46 million UK individuals aged 15 to 74 . The online sample was also compared with offline UK samples of the same age group, and is comparable in terms of working status, income, marital status, children in household and urban through to rural location (Northern Alliance and Ipsos MediaCT, 2011, p. 13).

\section{Analytical methods}

We used LCA to model the underlying latent groupings of respondents in both the DCMS and BFI data. We utilised the poLCA function and module (version 1.4.1) of $\mathrm{R}$ (version 3.6.1 'Action of the toes'). In all cases, we evaluated two to ten potential classes running 20 models in each case to avoid potential local minima. We selected the overall model with the lowest Bayesian Information Criterion (BIC). Details of each analysis are in the analytical methods section below. In the DCMS data we sought to identify the grouping (latent classes) of 'culture' attendees (i.e. individuals' range of art and culture consumption). In the case the BFI data, we sought to identify the groups (latent classes) that best model:

- Film genres preferred.

- Film genres watched.

${ }^{2}$ It also covers children aged 5 to 15 years old in England, which we do not draw on.
We used the BFI definition of genres because we are using their respective survey data. We examined film genres themselves separate from individual preferences and here we clustered film genre data by variable not respondent. Cluster analysis iteratively links cases or variables by their statistical closeness from a starting point where all are discrete until all cases or variables are within one cluster. As we were clustering the variables (not respondents) we could draw on a measure of the potential reliability of clusters. We used the pvclust package (version 2.0.0) in $\mathrm{R}^{3}$. The pvclust package allows for an assessment of the certainty/uncertainty in hierarchical cluster analysis. For each cluster in the hierarchy, probabilities ( $p$-values) are calculated via multiscale bootstrap resampling based on the BIC and Akaike Information Criterion (AIC). The $p$-value of a cluster is a value that indicates how strongly the cluster is supported by data between 0 (not at all) and 1 (completely).

The final models utilise binary logistic regression. Binary logistic regression (see Table 13) is a classification algorithm that seeks to assign observations to a discrete set of classes. Unlike linear regression that outputs a continuous value for the target variable, binary logistic regression transforms its output via a logistic sigmoid function to return a probability value that can be mapped to one of two discrete classes. We can assess the quality of the model based on how well it fits the data ( $k$ comparison with a model lacking predictive variables and the Hosmer and Lemeshow test) how much variance is explained (Pseudo $\mathrm{R}^{2}$ ) and the proportion of cases correctly predicted by the model. The binary regression was undertaken via the glm package (version 3.6.1) in R. See software availability for R scripts used for analysis (Yates et al., 2019)

\section{Preferences, attendance and perceptions of film}

This section discusses the findings in relation to our framework of analysis that addresses preferences, attendance, and perceptions of film and cultural consumption, investigating how these are related to socio-economic, status and wider cultural preferences.

\section{Film in the context of other cultural forms}

The first part of our analysis sought to assess where the general consumption of films sits against overall cultural consumption. Drawing on data from the 'Taking Part' survey, we undertook an LCA (see Figure 1 and Table 1) using the questionnaire items that assessed attendance at 22 forms of cultural activity (ranked Pr6: weekly attendance to Pr1: no attendance). Table 2 shows the distribution of these three latent classes within the dataset:

- Class 1: general consumers who have a high probability of consuming a wide range of culture, such as films, theatre, music and art exhibitions. Film has the highest probability of consumption.

- Class 2: limited consumers, who have a low probability of consuming culture across all areas. Film at the cinema has the highest consumption, followed by live music.

- Class 3: general consumers with specific cultural interests who have a high probability of consuming culture across all

\footnotetext{
${ }^{3}$ All analyses were run in RStudio under MacOS.
} 
Cultural Affinity Classes for Arts Attendance No Regression
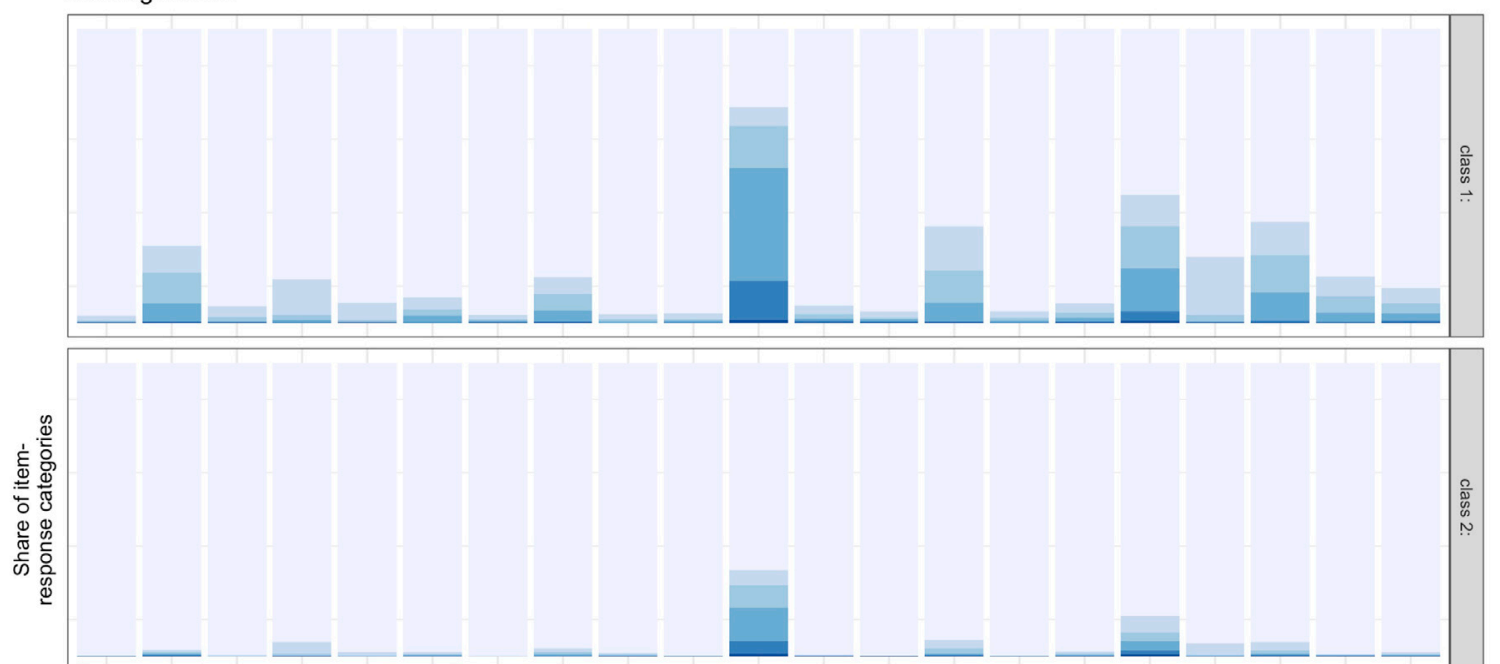

Weekly (6) $0<$ Once per year (2) Never (1)

늠
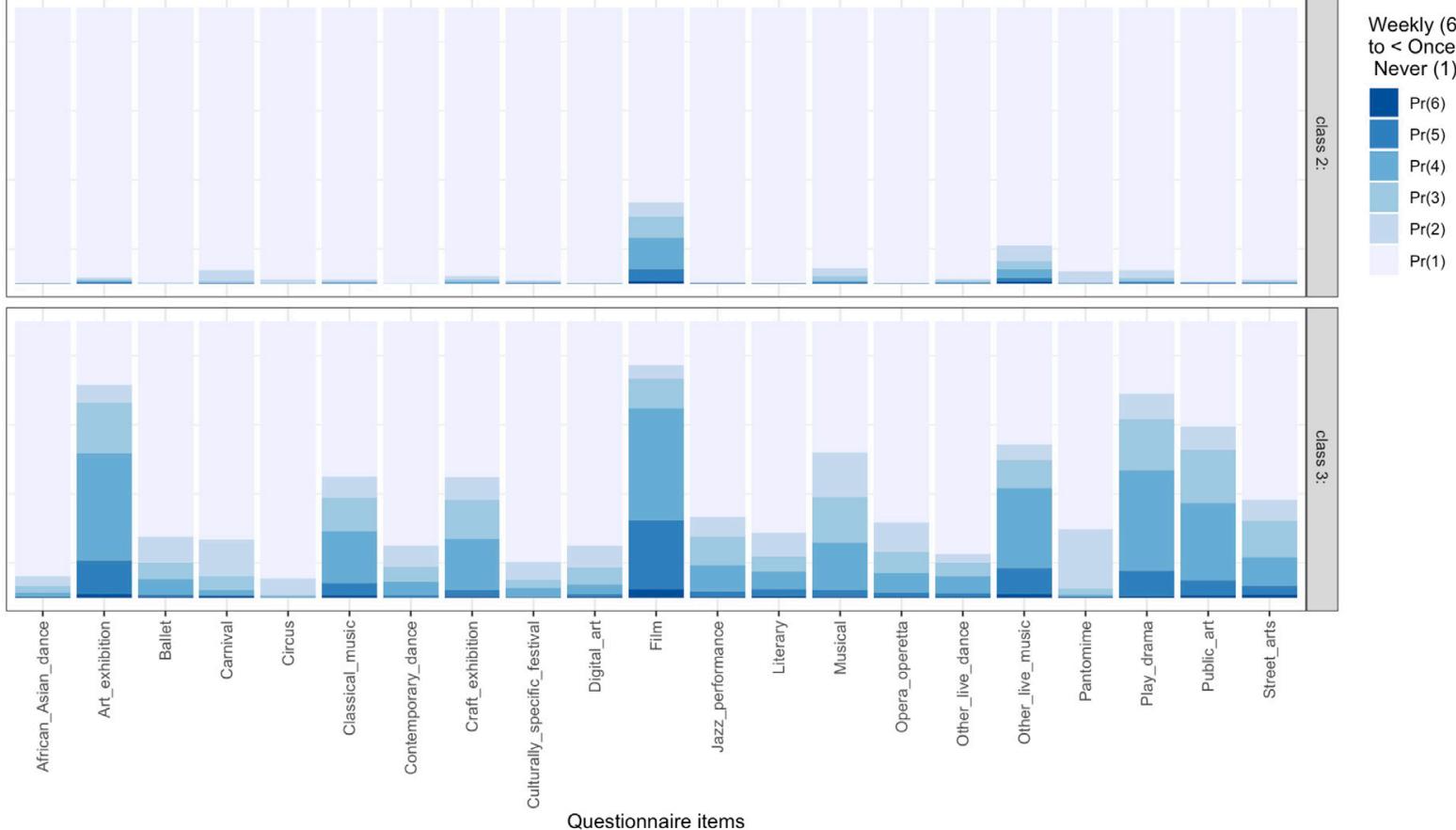

Figure 1. Latent class plot of arts attendance and Bayesian information criterion plots for latent class analysis (LCA) models.

\begin{tabular}{|l|l|l|l|l|l|l|l|}
\hline \multicolumn{7}{|c|}{ Table 1. Bayesian information criterion (BIC) values for tested latent classes. } \\
\hline \# Classes & II & df & BIC & AIC & II_ratio & Chi & Entropy \\
\hline $\mathbf{2}$ & -90252.92 & 9960 & 182452.8 & 180927.8 & 57629.47 & $5.56 \mathrm{E}+19$ & 0 \\
\hline $\mathbf{3}$ & -89173.13 & 9854 & 181271.3 & 178980.3 & 55469.88 & $2.30 \mathrm{E}+17$ & 0.452 \\
\hline $\mathbf{4}$ & -88783.86 & 9748 & 181470.9 & 178413.7 & 54691.35 & $2.59 \mathrm{E}+16$ & 0.596 \\
\hline $\mathbf{5}$ & -88411.69 & 9642 & 181704.6 & 177881.4 & 53947 & $1.42 \mathrm{E}+16$ & 0.587 \\
\hline $\mathbf{6}$ & -88144.07 & 9536 & 182147.5 & 177558.1 & 53411.76 & $1.66 \mathrm{E}+16$ & 0.614 \\
\hline $\mathbf{7}$ & -87927.89 & 9430 & 182693.2 & 177337.8 & 52979.41 & $1.72 \mathrm{E}+15$ & 0.629 \\
\hline $\mathbf{8}$ & -87770.78 & 9324 & 183357.1 & 177235.6 & 52665.2 & $4.47 \mathrm{E}+15$ & 0.552 \\
\hline $\mathbf{9}$ & -87627.86 & 9218 & 184049.3 & 177161.7 & 52379.36 & $4.38 \mathrm{E}+15$ & 0.603 \\
\hline $\mathbf{1 0}$ & -87462.68 & 9112 & 184697.1 & 177043.4 & 52048.99 & $3.32 \mathrm{E}+14$ & 0.475 \\
\hline
\end{tabular}

Table 2. Percentage of latent class membership - arts attendance.

\begin{tabular}{|l|l|l|}
\hline \% predicted class memberships (by modal posterior prob.) & & \\
\hline Class 1: 'paucivores' & Class 2:'inactives' & Class 3: 'omnivores' \\
\hline 51.49 & 38.37 & 10.14 \\
\hline
\end{tabular}


categories. The probability of them attending film at the cinema is highest of all three groups.

This indicates, first, that all the three classes are more likely to consume film at the cinema than engage in any other form of cultural activity. Second, our evidence aligns well with Chan \& Goldthorpe's (2010) approach, as our latent classes could also be understood as 'omnivores' (Class 3) , 'paucivores' (Class 1) and 'inactives' (Class 2). However, it is important to note that the 'limited' or 'inactives' group (Class 2) does still engage with cinema.

\section{Locating film genre and film genre preferences}

The next step is to assess if there was any differentiation within film consumption, which we do by asking:

1. Are film genres, in and of themselves, differentiated by consumer preferences?

2. Are consumers differentiated into latent classes by stated genre preferences?

3. Are consumers differentiated into latent classes by actual film genre viewing?

To address the first of these questions we examined how the variables for film genre preference clustered in the BFI survey data (Northern Alliance and Ipsos MediaCT, 2011). The BFI split genres for their preference questions into: Arthouse, Foreign language film, Romance, Romantic comedy,
Drama, Comedy, Action, Thriller, Family Film, Fantasy, Sci-fi, Classic, and Documentary. We removed War, Cowboy and Western, Gangster and Historical, as there were 7 or fewer responses for each of those. Our analysis shows that film genres organise into distinct clusters with high probability (over 95\%) as presented in Figure 2. The clusters that we identify appear to be at two levels.

1) First there are 5 distinct sub-groups (clusters):

1. Arthouse and foreign language film

2. Romance and romantic comedy

3. Drama, comedy, action and thriller

4. Fantasy and sci-fi

5. Classic and documentary

2) At a second level, arthouse and foreign language films are clearly separate from all the other genres.

\section{Film genre preferences}

To address whether people are differentiated as latent classes by genre preferences, we undertook an LCA on the same BFI genre preference dataset. Figure 3 shows the distribution of probable genre preference for each latent class and the BIC values for the ten LCA models evaluated. Table 3 presents BIC values for different class models and Table 4 presents the distribution of these latent classes within the dataset.

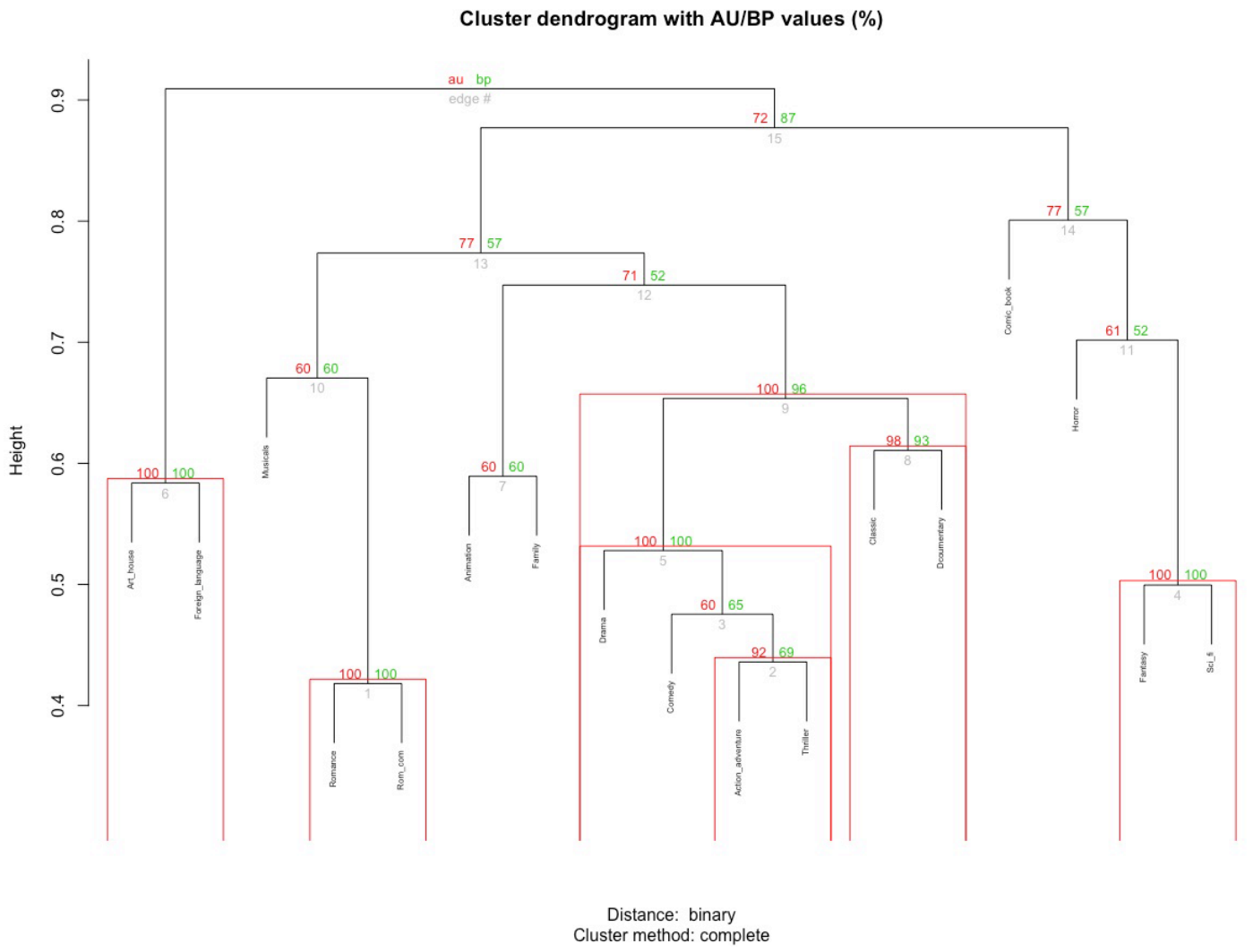

Figure 2. Genre clusters with statistical significance (over 95 is good). AU - approximately unbiased, BP - bootstrap probability. 


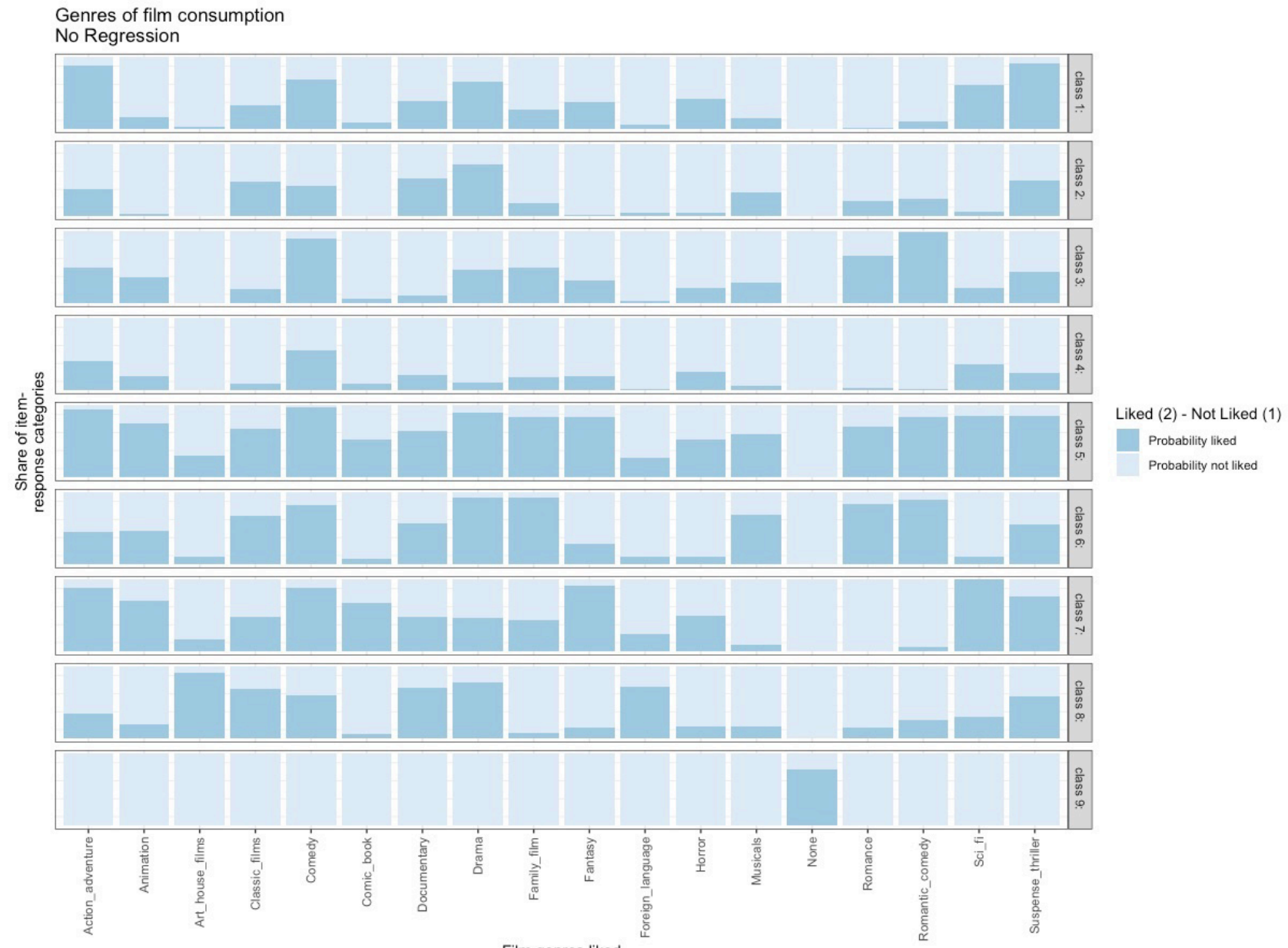

Figure 3. Latent class plot of film genre preference and Bayesian information criterion (BIC) plots for latent class analysis (LCA) models.

Table 3. Bayesian information criterion (BIC) values for tested latent classes. AIC

- Akaike Information Criterion.

\begin{tabular}{|l|l|l|l|l|l|l|l|}
\hline \# Classes & LI & df & BIC & AIC & II_ratio & Chi & Entropy \\
\hline $\mathbf{2}$ & -20189.5 & 1999 & 40660.9 & 40453.01 & 11620.898 & 191260.9 & 0 \\
\hline $\mathbf{3}$ & -19541.34 & 1980 & 39509.33 & 39194.68 & 10324.572 & 156913.6 & 0.632 \\
\hline $\mathbf{4}$ & -19135.14 & 1961 & 38841.68 & 38420.28 & 9512.167 & 169717.3 & 0.774 \\
\hline $\mathbf{5}$ & -18857.43 & 1942 & 38431.02 & 37902.86 & 8956.748 & 245999.1 & 0.696 \\
\hline $\mathbf{6}$ & -18657.13 & 1923 & 38175.18 & 37540.26 & 8556.151 & 132227.3 & 0.799 \\
\hline $\mathbf{7}$ & -18558.73 & 1904 & 38123.13 & 37381.46 & 8359.346 & 128391.2 & 0.743 \\
\hline $\mathbf{8}$ & -18471.05 & 1885 & 38092.54 & 37244.11 & 8183.997 & 136173.3 & 0.741 \\
\hline $\mathbf{9}$ & -18398.56 & 1866 & 38092.31 & 37137.12 & 8039.01 & 146653.7 & 0.729 \\
\hline $\mathbf{1 0}$ & -18332.73 & 1847 & 38105.4 & 37043.46 & 7907.346 & 187060.6 & 0.696 \\
\hline
\end{tabular}

Table 4. Percentage latent class membership - film genre preferences.

\begin{tabular}{l|l|l|l|l|l|l|l|l|}
\hline $\begin{array}{l}\text { \% predicted class memberships } \\
\text { (by modal posterior prob.) }\end{array}$ & & & & & \\
\hline Class 1 & Class 2 & Class 3 & Class 4 & Class 5 & Class 6 & Class 7 & Class 8 & Class 9 \\
\hline $17.58 \%$ & $14.24 \%$ & $14.10 \%$ & $12.72 \%$ & $10.85 \%$ & $9.87 \%$ & $8.06 \%$ & $7.42 \%$ & $5.16 \%$ \\
\hline
\end{tabular}


From this analysis we can identify nine latent classes of film genre preferences, which are detailed in Table 5. These film genres denote where there is a greater than $50 \%$ chance that members are likely to prefer films of that type.

If we compare these nine latent classes across a range of social and economic factors, we can note some key correspondences.
The predicted latent class membership for each respondent was compared with five categorical variables using a $\mathrm{X}^{2}$ test for independence (see Table 6, Table 7, and Table 8):

- Gender (man or woman).

- Age (15-24; 25-34; 35-54; or 55+).

Table 5. Latent class genre preference definitions.

\begin{tabular}{|c|c|c|}
\hline Latent class & Description & Genres most likely to be preferred in order of importance (probability $>50 \%$ ) \\
\hline Class 1 & Suspense and action & Suspense thriller; Action adventure; Comedy; Drama; Sci-fi \\
\hline Class 2 & Drama documentary & Drama; Documentary; Suspense thriller \\
\hline Class 3 & Romantic comedy & Romantic comedy; Comedy; Romance \\
\hline Class 4 & Comedy & Comedy/very limited engagement as all probabilities below $50 \%$ \\
\hline Class 5 & Mainstream film & All film types other than foreign language and arthouse films \\
\hline Class 6 & Family film & $\begin{array}{l}\text { Drama; Family film; Romantic comedy; Romance; Comedy; Musicals; Classic films; } \\
\text { Documentary; Suspense thriller }\end{array}$ \\
\hline Class 7 & Sci-fi-fantasy-action & Sci-fi; Fantasy; Action adventure; Comedy; Suspense thriller; Animation; Comic book; Horror \\
\hline Class 8 & $\begin{array}{l}\text { Arthouse and foreign } \\
\text { language }\end{array}$ & $\begin{array}{l}\text { Arthouse films; Drama; Foreign language; Documentary; Classic films; Comedy; Suspense } \\
\text { thriller }\end{array}$ \\
\hline Class 9 & No preference & No genre preference \\
\hline
\end{tabular}

Table 6. Latent class genre $\mathrm{X}^{2}$ by key variables.

\begin{tabular}{|l|l|l|l|l|l|l|}
\hline Crosstabulation & $\mathbf{2}$ & $\mathbf{n}$ & $\mathbf{d f}$ & $\mathbf{s i g}$ & Cramers V & effect size \\
\hline Film genre and education & 99.289 & 2036 & 24 & 0.0000 & 0.1275 & Small \\
\hline Film genre and income & 22.913 & 2036 & 8 & 0.0035 & 0.1061 & Small \\
\hline Film genre and gender & 389.567 & 2036 & 8 & 0.0000 & 0.4374 & Large \\
\hline Film genre and age & 255.831 & 2036 & 24 & 0.0000 & 0.2047 & Medium \\
\hline Film genre and area & 54.588 & 2036 & 24 & 0.0004 & 0.0945 & Small \\
\hline
\end{tabular}

Table 7. Bayesian information criterion (BIC) values for tested latent classes.

\begin{tabular}{|l|l|l|l|l|l|l|l|}
\hline \# Classes & II & df & BIC & AIC & II_ratio & Chi & Entropy \\
\hline $\mathbf{2}$ & -7091.283 & 112 & 14296.85 & 14212.57 & 776.85976 & 1148.2895 & 0 \\
\hline $\mathbf{3}$ & -6876.917 & 104 & 13929.06 & 13799.83 & 348.12719 & 412.9445 & 0.685 \\
\hline $\mathbf{4}$ & -6807.627 & 96 & 13851.44 & 13677.25 & 209.54815 & 273.62482 & 0.766 \\
\hline $\mathbf{5}$ & -6772.999 & 88 & 13843.13 & 13624 & 140.29229 & 185.84788 & 0.673 \\
\hline $\mathbf{6}$ & -6746.191 & 80 & 13850.46 & 13586.38 & 86.67607 & 91.3351 & 0.675 \\
\hline $\mathbf{7}$ & -6738.975 & 72 & 13896.98 & 13587.95 & 72.24405 & 63.60671 & 0.834 \\
\hline $\mathbf{8}$ & -6734.175 & 64 & 13948.33 & 13594.35 & 62.64495 & 60.00259 & 0.698 \\
\hline $\mathbf{9}$ & -6729.7 & 56 & 14000.33 & 13601.4 & 53.69503 & 51.51241 & 0.689 \\
\hline $\mathbf{1 0}$ & -6727.491 & 48 & 14056.86 & 13612.98 & 49.27621 & 45.35254 & 0.778 \\
\hline
\end{tabular}

Table 8. Percentage latent class membership - film genre preferences.

\begin{tabular}{|c|c|c|c|c|c|c|c|c|}
\hline $\begin{array}{l}\% \text { predicted class memberships } \\
\text { (by modal posterior prob.) }\end{array}$ & & & & & & & & \\
\hline Class 1 & Class 2 & Class 3 & Class 4 & Class 5 & Class 6 & Class 7 & Class 8 & Class 9 \\
\hline $17.58 \%$ & $14.24 \%$ & $14.10 \%$ & $12.72 \%$ & $10.85 \%$ & $9.87 \%$ & $8.06 \%$ & $7.42 \%$ & $5.16 \%$ \\
\hline
\end{tabular}


- Income (below $£ 30,000$ or above $£ 30,000$ ).

- Education (no qualification, GCSEs (or equivalent), A Levels (or equivalent), or degree (or above).

- Location (city, suburb, town, village or rural area).

The plots in Figure 4 indicate the residuals and contributions for each cell in the analysis. From this we can note the following:

- Women are more likely to be in the 'Romantic comedy' and 'Family film' latent classes. Men are more likely to be in the 'Suspense and action', 'Comedy' and 'Sci-fi, fantasy and action' latent classes.

- Older people (55+) are substantively more likely to be in the 'Drama and documentary' latent class. Younger people (15-24) are more likely to be in the 'Romantic comedy' and 'Comedy' latent classes.

- Income only has a small effect, with poorer people (under $£ 30,000$ pa) being more likely to be in the 'Drama and documentary' or 'No genre preference' categories.

- People with an income of over $£ 30,000$ pa are more likely to be members of the 'Specialised' film latent class.

- Those with degree level or higher qualifications were more likely to reside in the 'arthouse and foreign language' film latent class group.

- Those with no education higher than Level 3 were more likely to reside in the 'Comedy' latent class.

- Those living in cities are more likely to be members of the 'arthouse and foreign language' film latent class than those in suburban or village/rural areas.

These results suggest that consumers people with a preference for 'arthouse and foreign language' film earn over $£ 30,000$ pa, to live in cities and are more highly educated than those in other latent classes.

\section{Film attendance}

To ascertain what types of film respondents actually watched (on television, online or at the cinema) we used the BFI survey questions about film viewing via different media. Here, the genres were:

- Animated

- Blockbuster

- Famous cast

- Foreign language

- Independent

- Other (none of above)

- Don't know
The survey asked if respondents had watched these types of films in the last 12 months in each of the following media/locations:

- Cinema

- TV

- DVD

- Download

- Mobile device

- Aeroplane

From this data, we were able to determine whether films of each genre type had been watched, no matter the medium. Taking this data, we undertook LCA analysis and identified five latent classes, as shown in Figure 5.

We interpret the five latent classes as:

- 1: all films - people who are highly likely to watch most types of films, including independent and foreign language films.

- 2: mainstream (know) - people who are likely to watch most mainstream films but not independent or foreign language films.

- 3: other - people who, if they watched film, indicated that they watched other film types than those offered.

- 4: mainstream (don't know) - people who mostly watched mainstream cinema but were unsure of what other genres of film they watched.

- 5: limited- people who did not know, or were at best unsure about, what genre of films they watched.

If we compare these 5 latent classes with the 9 classes via a $\mathrm{X}^{2}$ test for independence between we find a significant association with a medium effect size $X^{2}(32, n=2036)=435.022, p=$ 0.000 , Cramers $\mathrm{V}=0.2311$. The residual and contribution plots (see Figure 6) show that the key effects are: first, that those with 'No genre preference' also do not watch film; second that those who prefer 'arthouse and foreign language' film are more likely to fall in the 'All film' category and that those who prefer 'Drama' into the watched 'Other' film category.

A key conclusion is that there is a distinguishable genre of arthouse and foreign language film and there is a specific group of consumers who prefer such films and who also consume films across many genres. Furthermore, those who view many different genres also watch arthouse and foreign language films, even if they do not prefer these. In fact, $80.1 \%$ of those who are in the 'arthouse and foreign language' film genre group are also members of Class 1 , most likely to watch any film genre.

This result is more complex than that for wider cultural attendance. As with Chan \& Goldthorpe (2010), we have a latent class of consumers that might be understood as 'omnivores' 


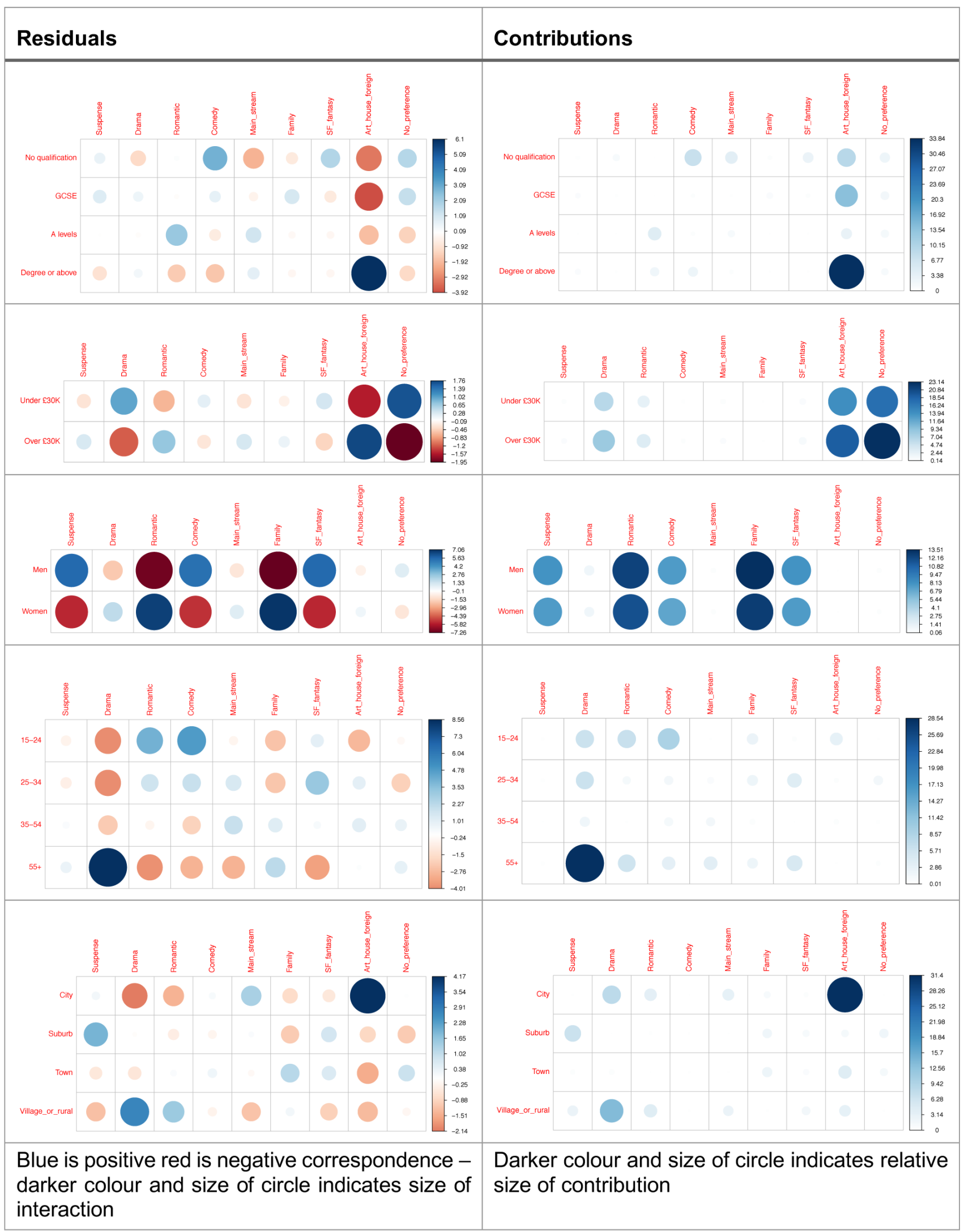

Figure 4. Residuals and contributions from $\mathrm{X}^{2}$ analyses of genre preference. 


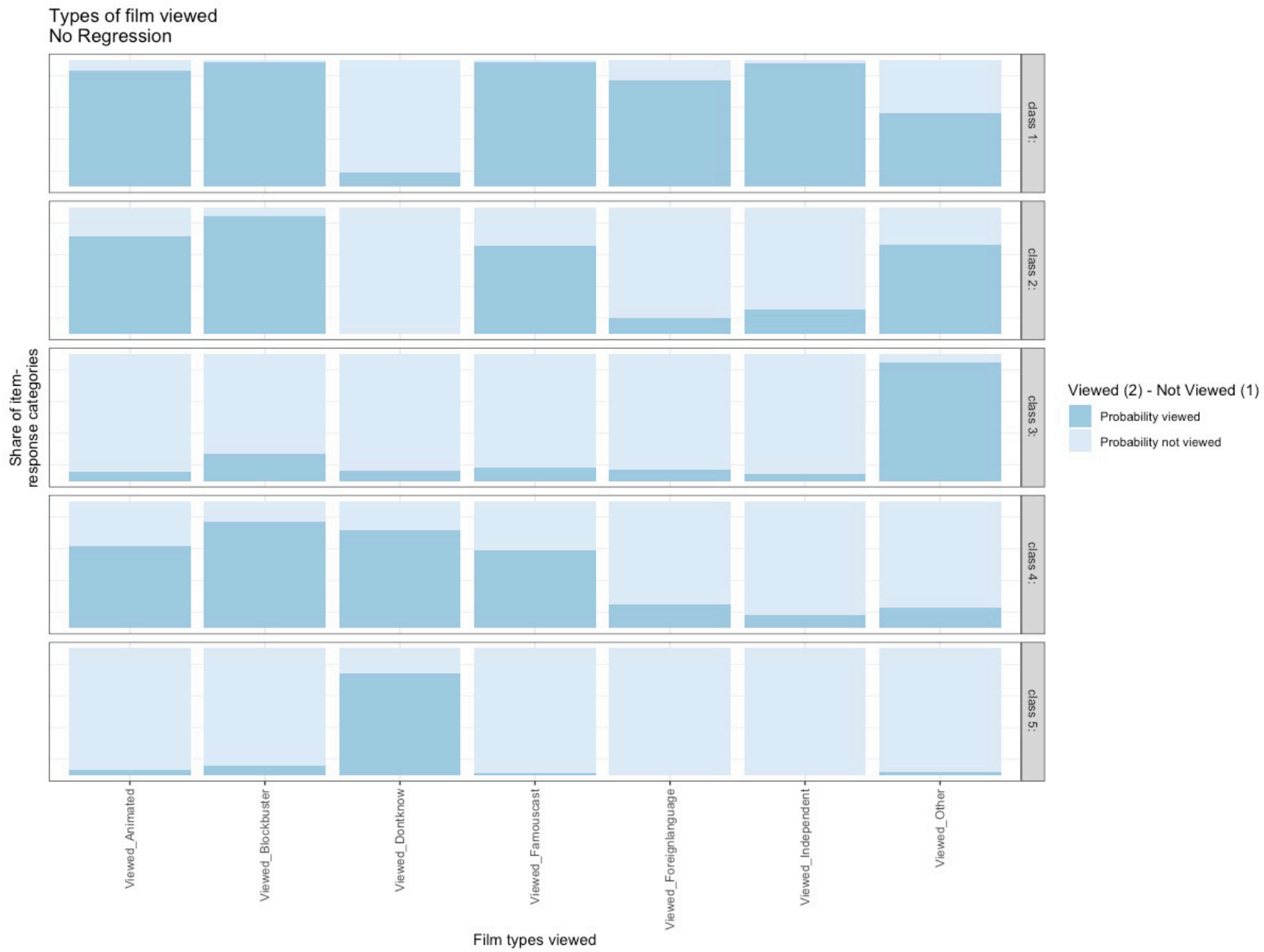

Figure 5. Latent class plot of film genre viewing and Bayesian information criterion (BIC) plots for Latent class analysis (LCA) models.

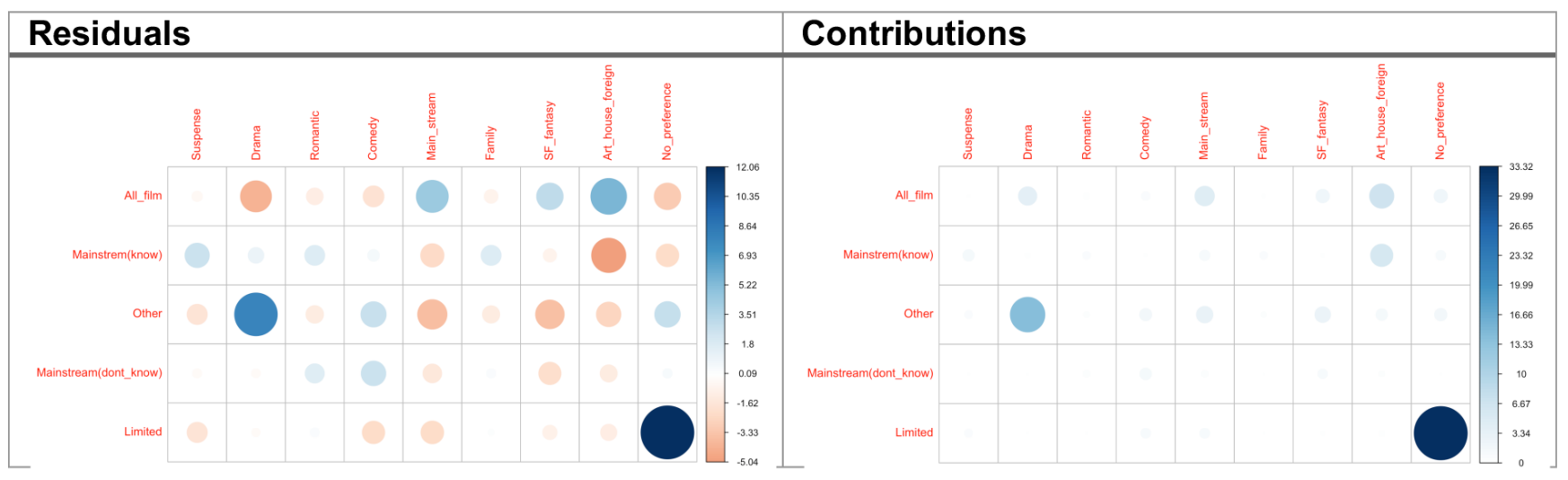

Figure 6. $\mathrm{X}^{2}$ of genre preference and genres watched. 
(Class 1). Class 5 are 'inactives' in terms of film. Classes 2, 3 and 4 appear to represent limited consumption - only consuming either mainstream or another unspecified type of film. Next, we considered these film consumption classes against our social and economic variables. Via separate $\chi 2$ tests for independence, we found that all variables except Gender showed a statistically significant correspondence to the five latent classes (Table 9). From an examination of the plots of contributions and residuals (Figure 7) we conclude:

- Those with over $£ 30,000$ pa income were likely to be in the 'All films' latent class, with lower income respondents in the 'Other' and 'Limited' latent classes.

- Those aged 25 to 34 years were most likely to be in the 'All films' latent class and least likely to be in the 'Other' latent class. The probability of older respondents (55+) was the exact opposite - most likely to be in the 'Other' class and less likely to be in the 'All films' class.

- Those with a degree or above were far more likely to be in the 'All film' latent class, with those holding GCSE level or no qualifications being more likely to be in the other four classes.

- Those living in cities were the most likely to be in the 'All film' latent class, whereas those living in suburban or village/rural areas were more likely to be in the 'Mainstream (know)' latent class.

Those who watch arthouse or foreign language films are more likely to:

- Fall in the 'All film' latent class.

- Be aged 55 or under.

- Earn over $£ 30,000$ per annum.

- Hold a degree or higher qualification.

- Live in a city.

To test this assertion fully we undertook a binary logistic regression to fit a model based on the five expected demographic factors of the 'All film' latent class: age, gender, education, income and urban location. The model used the glm package in $\mathrm{R}$ (see Table 10). The full model containing all predictors was statistically significant $\left(\mathrm{X}^{2}(5, \mathrm{~N}=2036)=156.7\right.$, $\mathrm{p}<0.000$ ). The model as a whole only explained between $7.4 \%$ (Cox and Snell R square) and 9.9\% (Nagelkerke R squared) of the variance in membership of the 'All film' latent class. It correctly classified $61.8 \%$ of cases. Four of the independent variables made a unique, statistically significant contribution to the model (education, age, location and income). The strongest predictor of all was level of education, with those who held a first degree or higher being 2.48 times more likely to be in the 'All film' class than anyone else, controlling for other factors. Living in a city makes respondents 2.02 times more likely to be in this class. Youth also contributes - every 5 years younger than 75 increases the likelihood of being in this class by $17 \%$. Earning over $£ 30,000$ per annum increases your likelihood 1.31 times. Therefore, being highly educated, younger, earning a higher income, and living in a city makes someone more likely to be in the 'All film' latent class.

Interpretations of this result include that cultural taste - such as consumption of film - is tied but weakly, to socio-economic factors and that a large proportion of film viewers (in all genres) are have omnivore patterns of film consumption. To assess this further, we need to address any implications of other cultural consumption in shaping consumer preferences, attendance and perceptions.

\section{Perception within cultural consumption}

To explore these options, we first explored whether respondents' perceptions of various cultural forms corresponded with their genre preferences. Second, we sought to expand the binary logistic regression model above to see if adding these perception factors increased the accuracy of the model. The BFI survey (Northern Alliance and Ipsos MediaCT, 2011) asked respondents about their perception of 15 areas of cultural activity:

1. Film

2. Classical music

3. Pop/rock music

4. TV

5. Theatre

6. Literature

7. News

Table 9. $X^{2}$ results of film watched latent class and key social variables.

\begin{tabular}{|l|l|l|l|l|l|l|}
\hline Crosstabulation & $\mathbf{X}^{2}$ & $\mathbf{n}$ & $\mathbf{d f}$ & $\mathbf{s i g}$ & Cramers V & effect size \\
\hline Film class vs income & 37.8317069 & 2036 & 4 & 0.0000 & 0.1363 & Small \\
\hline Film class vs age & 136.62829 & 2036 & 12 & 0.0000 & 0.1496 & Small \\
\hline Film class vs education & 84.5092141 & 2036 & 12 & 0.0000 & 0.1176 & Small \\
\hline Film class vs gender & 3.66150311 & 2036 & 4 & 0.4537 & 0.0424 & N/A \\
\hline Film class vs area & 66.7566877 & 2036 & 12 & 0.0000 & 0.1045 & Small \\
\hline
\end{tabular}




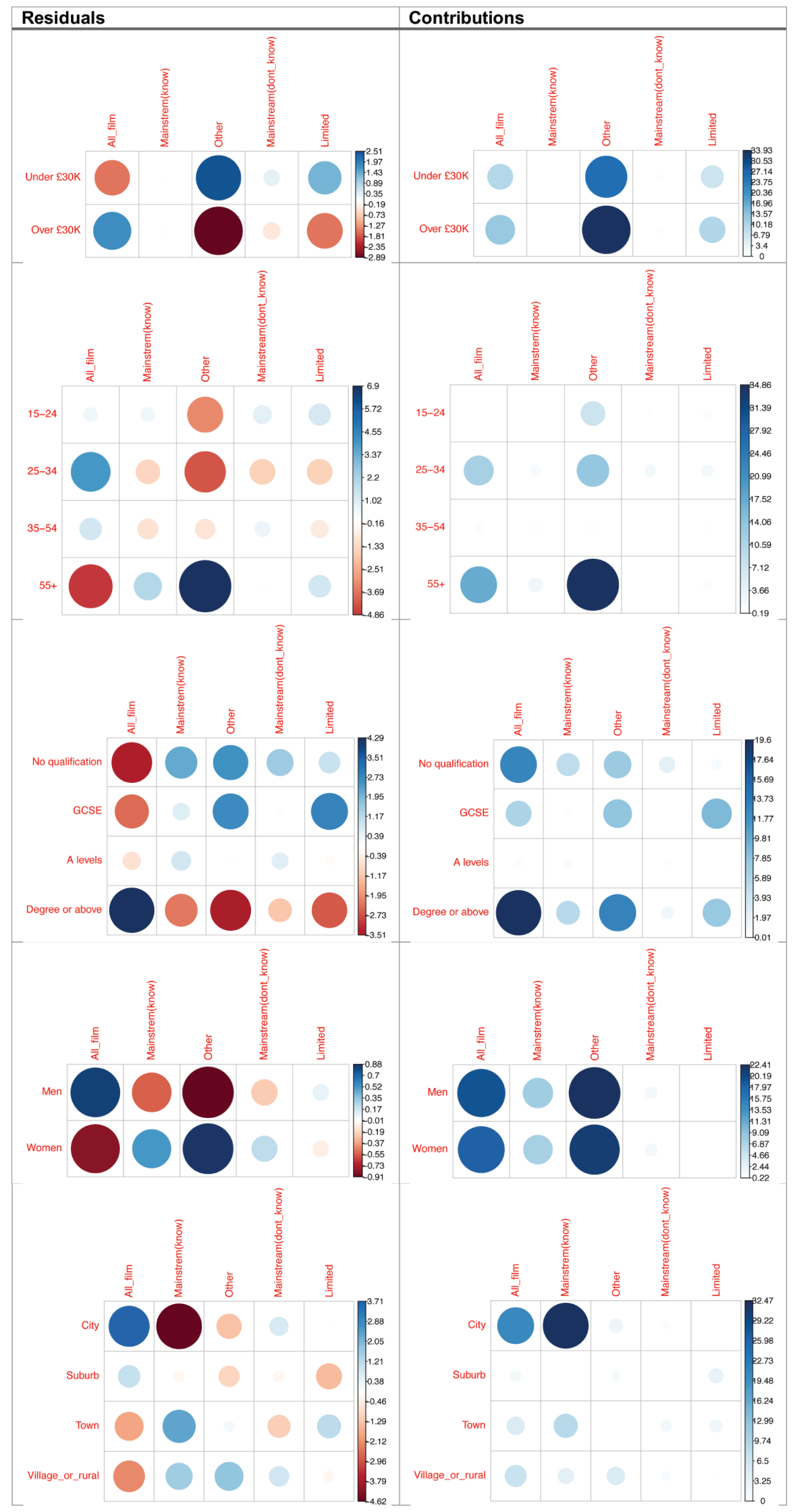

Figure 7. X2 residuals and contributions for film genre watched classes and social variables. 
Table 10. Binary logistic regression model of watching all film and key social variables.

\begin{tabular}{|c|c|c|c|c|c|c|c|c|}
\hline Coefficients & Estimate & Std. Error & $z$ value & $\operatorname{Pr}(>|z|)$ & & OR & Cl for OR $2.5 \%$ & $97.5 \%$ \\
\hline (Intercept) & 0.720 & 0.282 & 2.556 & 0.011 & * & 2.055 & 1.185 & 3.576 \\
\hline Education & 0.302 & 0.042 & 7.128 & 0.000 & *** & 1.354 & 1.246 & 1.472 \\
\hline Age & -0.162 & 0.025 & -6.464 & 0.000 & *** & 0.850 & 0.809 & 0.893 \\
\hline Gender & -0.127 & 0.093 & -1.367 & 0.171 & & 0.881 & 0.735 & 1.056 \\
\hline Location & -0.233 & 0.044 & -5.306 & 0.000 & *** & 0.792 & 0.727 & 0.863 \\
\hline Income & 0.268 & 0.100 & 2.685 & 0.007 & ** & 1.307 & 1.075 & 1.589 \\
\hline 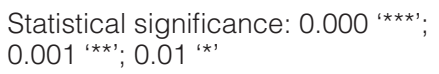 & & & & & & & & \\
\hline
\end{tabular}

\section{Art}

9. Video games

10. Watching sport

11. Taking part in sport

12. Pubs and clubs

13. Restaurants

14. Countryside

15. Religion

The survey asked respondents to agree or disagree with the following perception about each of these cultural activities:

1. Entertaining

2. Sociable

3. Informative/educational

4. Relaxing

5. Good at providing escapism

6. Thought provoking

7. Rewarding

8. Good for people's self-development

9. Fashionable

10. Inspirational

11. Emotional/moving

12. Good for people's sense of well-being

13. Boring

14. Has a negative effect on people/society

15. Has artistic value

16. Exciting
As noted in the research methods section above, we statistically explored the responses to the survey questions using LCA and cluster techniques. We found that the results of such analyses differentiated between those with negative views (such as film is 'boring') and those with ever-greater numbers of positive perceptions of culture - effectively forming an ordinal measure. This made it reasonable to simplify the analysis by calculating a score for each cultural activity for each respondent. Negative items (boring/negative effect) scored -1 and positive ones +1 . From this, we created an ordinal measure by using binVariable of the $\mathrm{R}$ package RcmdrMisc. The variables were binned into 4 categories using k-means clustering and marked as: 'Negative', 'Limited', 'Positive', or 'Very positive'. We used these measures to compare perceptions of these 15 cultural areas against our film genre preference latent classes via a $\mathrm{X}^{2}$ test for independence - see Table 11 .

The next step is to consider if, and how such perceptions affect preferences for, and consumption of, arthouse and foreign language film. Drawing on the analyses in Table 10, we note the following correspondences:

- Consumers who have a negative view of film, TV, news, and countryside are likely to be in the 'Comedy' latent class - which had the lowest overall likelihood of liking any film genre. Those who have a positive view are likely to be in the 'Mainstream' latent class.

- Consumers who have a negative view of classical music, arts and literature are also likely to be in the 'Comedy' latent class. In contrast, those with a positive view are likely to be in both the 'Mainstream' and the 'Specialised' film latent classes.

- Consumers with a positive perception of pop/rock music are likely to be in the 'Mainstream' class; those with a negative view of pop/rock are likely to be in the 'Drama' and 'Comedy' latent classes.

- Consumers with positive views of videogames are likely to be in the 'Mainstream' and 'SF/Fantasy' classes; and those with a negative view in the 'Drama' class. 
Table 11. $X^{2}$ results of film genre preferences and perceptions of culture.

\begin{tabular}{|l|l|l|l|l|l|l|}
\hline Crosstabulation & $\mathbf{X}^{\mathbf{2}}$ & $\mathbf{n}$ & $\mathbf{d f}$ & $\mathbf{s i g}$ & Cramers V & effect size \\
\hline Genre vs Film perception & 344.939 & 2036 & 24 & 0.0000 & 0.2376 & Medium \\
\hline Genre vs classical music perception & 247.145 & 2036 & 24 & 0.0000 & 0.2012 & Medium \\
\hline Genre vs pop/rock music perception & 178.406 & 2036 & 24 & 0.0000 & 0.1709 & Medium \\
\hline Genre vs TV perception & 207.954 & 2036 & 24 & 0.0000 & 0.1845 & Medium \\
\hline Genre vs theatre perception & 270.153 & 2036 & 24 & 0.0000 & 0.2103 & Medium \\
\hline Genre vs literature perception & 275.168 & 2036 & 24 & 0.0000 & 0.2123 & Medium \\
\hline Genre vs news perception & 134.928 & 2036 & 24 & 0.0000 & 0.1486 & Small \\
\hline Genre vs arts perception & 243.666 & 2036 & 24 & 0.0000 & 0.1997 & Medium \\
\hline Genre vs video games perception & 216.458 & 2036 & 24 & 0.0000 & 0.1883 & Medium \\
\hline Genre vs sports attendance perception & 95.057 & 2036 & 24 & 0.0000 & 0.1248 & Small \\
\hline Genre vs sports participation perception & 110.763 & 2036 & 24 & 0.0000 & 0.1347 & Small \\
\hline Genre vs pubs and clubs perception & 92.298 & 2036 & 24 & 0.0000 & 0.1229 & Small \\
\hline Genre vs restaurants perception & 161.436 & 2036 & 24 & 0.0000 & 0.1626 & Small \\
\hline Genre vs countryside perception & 164.694 & 2036 & 24 & 0.0000 & 0.1642 & Small \\
\hline Genre vs religion perception & 145.618 & 2036 & 24 & 0.0000 & 0.1544 & Small \\
\hline
\end{tabular}

- A positive view of sports attendance and participation is associated with the 'Mainstream' latent class, while a negative view of sports participation is only strongly linked to one latent class, 'Drama'.

- Consumers who have a negative view of restaurants, pubs and clubs are likely to be in the 'Comedy' latent class, while those who have a positive view are likely to be in the 'Mainstream' or 'Family' latent classes.

Given these correspondences, we looked to see if the inclusion of perceptions of cultural forms would improve our model of which consumers fall in the 'All film' latent class. We therefore undertook a binary logistic regression based on our five demographic factors and 15 perception measures. The model was run using the glm package in $\mathrm{R}$ (see Table 12). The full model containing all predictors was statistically significant $\left(\mathrm{X}^{2}(20, \mathrm{~N}=2036)=294.28, \mathrm{p}<0.000\right)$. The Hosmer and Lemeshow test (binary model) was non-significant (X-squared $=7.7078, \mathrm{df}=6, \mathrm{p}=0.2603$ ), indicating that the model was a good fit. The model as a whole only explained between $13.5 \%$ (Cox and Snell R square) and $17.9 \%$ (Nagelkerke R squared) of the variance in membership of the 'All film' latent class. It correctly classified $64.9 \%$ of cases. Comparing this to the model that did not include the perception variables, we found that this was a better fit ( $k=137.58, \mathrm{df}=15, \mathrm{p}<0.000)$.

Of the independent variables, 13 made a unique statistically significant contribution to the model. These were the same five as before (education, age, gender, location and income), with the addition of the perception of film, TV, theatre, art, pubs and clubs. The strongest predictor was education level, as those with a degree or higher were 2.00 times more likely to be in the "All film' class than those with no education at Level 3 or higher, controlling for other factors. Having a positive perception of film and arts had a greater positive impact on whether someone fell into this class or not. Having positive perceptions of classical music, pop/rock music, news, pubs and clubs also had smaller positive effects. Positive perceptions of TV and theatre lessened likely membership. Overall then, we can view our 'All film' latent class as likely to be people who are younger, more highly educated, with higher incomes, living in a city, with positive perceptions of film, the arts, pubs and clubs, music (classical and/or pop/rock) and news. They are less keen on TV and theatre.

As a final analysis we combined preference and practice for those who had both declared a preference for and had also watched arthouse and foreign language film in the last year (in any medium). These two groups are reasonably highly correlated though there are more people who watched arthouse and foreign language film in the last year than declared a liking for it $\left(\mathrm{X}^{2}(1,2036)=32.344, \mathrm{p}<0.000\right.$, phi $=0.126$ (medium effect). In the context of our discussion, this points to the contrast between preference and actual action. The model was run using the glm package in $\mathrm{R}$, for details see Table 10. The full model containing all predictors was statistically significant $\left(X^{2} \quad(20\right.$, 2036) $=182.33 \mathrm{p}<0.000)$. The Hosmer and Lemeshow test (binary model) was non-significant $\left(\mathrm{X}^{2}(6,2036)=9.2426\right.$, $\mathrm{p}=0.1604)$ indicating the model was a good fit. The model as a whole only explained between $8.5 \%$ (Cox and Snell R square) and $13.7 \%$ (Nagelkerke $\mathrm{R}$ squared) of the variance in membership of the preferred and watched group. It correctly classified $80.7 \%$ of cases. 
Table 12. Binary logistic regression model of watching all film and key social variables and arts perceptions.

\begin{tabular}{|c|c|c|c|c|c|c|c|c|}
\hline Coefficients & Estimate & Std. Error & $z$ value & $\operatorname{Pr}(>|z|)$ & & OR & CI for OR $2.5 \%$ & $97.5 \%$ \\
\hline (Intercept) & 0.222 & 0.319 & 0.694 & 0.488 & & 1.248 & 0.667 & 2.335 \\
\hline Perception of film & 0.096 & 0.022 & 4.441 & 0.000 & *** & 1.101 & 1.055 & 1.149 \\
\hline Perception of classical music & 0.040 & 0.022 & 1.782 & 0.075 & . & 1.040 & 0.996 & 1.087 \\
\hline Perception of pop/rock music & 0.034 & 0.020 & 1.684 & 0.092 & . & 1.035 & 0.994 & 1.077 \\
\hline Perception of TV & -0.052 & 0.020 & -2.652 & 0.008 & ** & 0.949 & 0.913 & 0.986 \\
\hline Perception of theatre & -0.040 & 0.020 & -2.055 & 0.040 & * & 0.960 & 0.924 & 0.998 \\
\hline Perception of literature & -0.016 & 0.019 & -0.867 & 0.386 & & 0.984 & 0.949 & 1.021 \\
\hline Perception of news & 0.045 & 0.027 & 1.668 & 0.095 & . & 1.046 & 0.992 & 1.104 \\
\hline Perception of arts & 0.076 & 0.022 & 3.519 & 0.000 & $\star \star \star *$ & 1.079 & 1.035 & 1.127 \\
\hline Perception of games & 0.034 & 0.025 & 1.370 & 0.171 & & 1.034 & 0.986 & 1.085 \\
\hline Perception of sport attend & -0.035 & 0.023 & -1.492 & 0.136 & & 0.966 & 0.922 & 1.011 \\
\hline Perception of sport participate & 0.007 & 0.024 & 0.296 & 0.767 & & 1.007 & 0.961 & 1.056 \\
\hline Perception of pubs and clubs & 0.068 & 0.028 & 2.481 & 0.013 & * & 1.071 & 1.015 & 1.131 \\
\hline Perception of restaurants & -0.029 & 0.030 & -0.972 & 0.331 & & 0.971 & 0.915 & 1.030 \\
\hline Perception of countryside & 0.014 & 0.021 & 0.679 & 0.497 & & 1.014 & 0.973 & 1.057 \\
\hline Perception of religion & -0.044 & 0.022 & -2.029 & 0.042 & * & 0.957 & 0.917 & 0.998 \\
\hline Education & 0.230 & 0.045 & 5.061 & 0.000 & *** & 1.259 & 1.151 & 1.376 \\
\hline Age & -0.180 & 0.030 & -6.065 & 0.000 & *** & 0.835 & 0.788 & 0.885 \\
\hline Gender & -0.150 & 0.104 & -1.451 & 0.147 & & 0.860 & 0.702 & 1.054 \\
\hline Location & -0.237 & 0.046 & -5.178 & 0.000 & 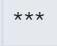 & 0.789 & 0.721 & 0.863 \\
\hline Income & 0.217 & 0.104 & 2.085 & 0.037 & * & 1.242 & 1.013 & 1.524 \\
\hline 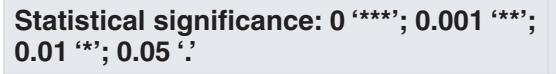 & & & & & & & & \\
\hline
\end{tabular}

Table 13. Binary logistic regression model of watching and liking specialised film and key social variables and arts perceptions.

\begin{tabular}{|c|c|c|c|c|c|c|c|c|}
\hline & Estimate & Std. Error & $z$ value & $\operatorname{Pr}(>|z|)$ & & OR & $\mathrm{Cl}$ for OR $2.5 \%$ & $97.5 \%$ \\
\hline (Intercept) & -1.120 & 0.387 & -2.892 & 0.004 & ** & 0.326 & 0.152 & 0.694 \\
\hline Perception of film & 0.084 & 0.026 & 3.266 & 0.001 & ** & 1.088 & 1.034 & 1.144 \\
\hline Perception of classical music & 0.036 & 0.027 & 1.340 & 0.180 & & 1.036 & 0.984 & 1.092 \\
\hline Perception of pop/rock music & -0.047 & 0.025 & -1.928 & 0.054 & $\cdot$ & 0.954 & 0.909 & 1.001 \\
\hline Perception of TV & -0.067 & 0.024 & -2.829 & 0.005 & ** & 0.935 & 0.892 & 0.979 \\
\hline Perception of theatre & -0.017 & 0.024 & -0.704 & 0.482 & & 0.984 & 0.939 & 1.030 \\
\hline Perception of literature & 0.002 & 0.023 & 0.086 & 0.932 & & 1.002 & 0.958 & 1.048 \\
\hline Perception of news & 0.011 & 0.032 & 0.340 & 0.734 & & 1.011 & 0.948 & 1.077 \\
\hline Perception of arts & 0.086 & 0.026 & 3.281 & 0.001 & ** & 1.090 & 1.035 & 1.148 \\
\hline Perception of games & -0.003 & 0.028 & -0.115 & 0.909 & & 0.997 & 0.942 & 1.054 \\
\hline Perception of sport attend & -0.016 & 0.028 & -0.572 & 0.568 & & 0.984 & 0.931 & 1.040 \\
\hline Perception of sport participate & 0.022 & 0.030 & 0.757 & 0.449 & & 1.023 & 0.965 & 1.084 \\
\hline Perception of pubs and clubs & -0.003 & 0.032 & -0.079 & 0.937 & & 0.997 & 0.936 & 1.062 \\
\hline Perception of restaurants & 0.001 & 0.036 & 0.021 & 0.983 & & 1.001 & 0.932 & 1.073 \\
\hline
\end{tabular}




\begin{tabular}{|c|c|c|c|c|c|c|c|c|}
\hline & Estimate & Std. Error & $z$ value & $\operatorname{Pr}(>|z|)$ & & OR & $\mathrm{Cl}$ for OR $2.5 \%$ & $97.5 \%$ \\
\hline Perception of countryside & -0.026 & 0.026 & -0.972 & 0.331 & & 0.975 & 0.925 & 1.026 \\
\hline Perception of religion & -0.041 & 0.027 & -1.550 & 0.121 & & 0.960 & 0.911 & 1.011 \\
\hline Education & 0.302 & 0.061 & 4.965 & 0.000 & $* \star *$ & 1.353 & 1.202 & 1.526 \\
\hline Age & -0.225 & 0.038 & -5.962 & 0.000 & 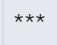 & 0.798 & 0.741 & 0.859 \\
\hline Gender & -0.094 & 0.128 & -0.730 & 0.465 & & 0.911 & 0.708 & 1.171 \\
\hline Location & -0.222 & 0.055 & -4.037 & 0.000 & $\star \star \star *$ & 0.801 & 0.718 & 0.892 \\
\hline Income & 0.400 & 0.124 & 3.229 & 0.001 & ** & 1.491 & 1.170 & 1.901 \\
\hline 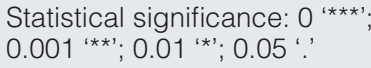 & & & & & & & & \\
\hline
\end{tabular}

Seven of the independent variables made a unique, statistically significant contribution to the model. These were education, age, location and income, along with a positive perception of film and art, and a negative perception of TV. The strongest predictor was level of education, with those who held a degree or higher being 2.48 times more likely to have declared a preference for and watched arthouse and foreign language films than those with no post-16 education, controlling for other factors. Living in a city increases the likelihood of being in this group by 1.95 times, as does being younger and earning a higher income. Having a positive perception of film and the arts has a positive impact on being a member of this latent class.

\section{Conclusion: patterns of consumption}

Our analysis confirms that film is one of the most consumed cultural forms, watched by a wide range of consumers, and offers a range of values and experiences to its consumers. We found statistical backing for our three main consumer types, namely general consumers who consume a wide range of genres and other culture, limited consumers who consume few films and do not consume other culture to any significant degree, and general consumers with specific interests, who consume a wide range of culture, but who also have specific interests, such as arthouse and foreign language film.

Although film genre is a feature in differentiating preferences and the choices consumers make, our analysis shows that arthouse and foreign language film, is a specifically different genre. It stands alone, in and of itself, in our clustering of genre preferences. Those who prefer arthouse and foreign language film also stand out as a separate latent class. Though many film consumers are 'omnivores' in terms of consuming a wide range of film genres, our analysis suggests those who prefer arthouse and foreign language film are a distinct group within that. Therefore, actual consumption of film does not neatly fit the model of 'omnivores', 'paucivores' and 'inactives' as defined by Chan \& Goldthorpe (2010) We therefore classify:
- 'Extensive omnivores', consumers who watch all genres and arthouse and foreign language film; they are general consumers with specific interests.

- 'Basic omnivores', consumers who watch all genres but who do not have a specific favourite genre such as arthouse and foreign language film; they are general consumers.

- Given most people watch film,' inactives' is not a strong group; they are limited consumers.

Our analysis suggests that film consumption is not completely free from consumers' economic capital and status. Although there is a range of links between preferences and consumption of different film genres and consumers' perceptions of other cultural forms. The distinctiveness of arthouse and foreign language film consumption may point to a cultural variation within different groups of 'omnivores', as noted by Hanquinet (2013). In overall terms, education, income, age and urban location are greater predictors of this than cultural perceptions. The combining of these factors, however, does not massively increase the predictive power of our analyses, nor does it explain the overall variance. This suggests that additional factors apart from the economic and status and cultural capital (namely education) and perceptions of other cultural forms, feature in film consumption.

There is considerable evidence that in the consumption of film there is a distinct group who displays omnivore behaviour, who are: more highly educated; have higher incomes; are younger, live in urban locations and have positive perceptions of other cultural forms. However, there are variations within this group, such as those who hold a preference for arthouse and foreign language film, whose social and economic profile does not differ greatly from that of the wider group, and who show a small number of differences in cultural preferences. This may indicate some individualised cultural consumption, however, the evidence for a persistent link to economic and cultural capital and status remains. 
In our analysis there is little to support the claim that the link to socio-economic status in cultural consumption has been broken and that cultural consumption is highly individualised (Bauman, 1998; Bauman, 2001). As with Chan \& Goldthorpe (2010), we have found that education is a key factor, with more advanced education participation linked to a more than doubling in the likelihood of being a general consumer of all types of film, or a consumer of arthouse and foreign language film. For Bourdieu (1984), education constitutes a key part of a person's cultural capital and underpins their socialisation and development of habitus. In Weberian approaches, education is also a key element of status. Our results then provide support for both of these positions.

To conclude, we therefore argue that there is limited evidence of a free play of eclectic cultural consumption. What we see is an appreciation by consumers of the relative value of a cultural form, their stated preferences and what they actually attend. The broad patterns of film consumption suggest that consumer choices are not eclectic, since there is an internal coherence to cultural choices that link with key social and cultural variables, as well as an element of choice. The patterns of cultural consumption we have identified show that there is an element of openness in consumption, and socio-economic and cultural profiles may shape but do not rigidly identify consumers. Further research needed to examine the preferences, motivations and contexts around the consumption of film and other culture. Research is needed to explore wider influences in learning to consume beyond formal education in shaping cultural appreciation, which includes examining the role of friendship networks, film and other cultural events and clubs. Research is needed to deepen understanding about how status forms through particular patterns of consumption in order to ascertain its relationship with socio-economic background and urban and rural residence.

\section{Data availability}

\section{Source data}

The dataset used in this paper is composed of responses to a British Film Institute (BFI) survey titled: 'Cultural Consumption' conducted by IpsosMORI in 2011. The BFI provide the survey dataset as appendix 4 of their larger report:

Northern Alliance and Ipsos MediaCT (2011) Opening our eyes: How film contributes to the culture of the UK (Report), London: British Film Institute. Available at: https://www.bfi.org. uk/about-bfi/policy-strategy/opening-our-eyes-how-film-contributes-culture-uk.
Duplicate copies of the dataset (without attributed DOI references) are available via both the Digital Humanities Institute (DHI) data repository at the University of Sheffield: https://www. dhi.ac.uk/san/btm/Data_122018/Cultural\%20Contribution.zip and direct via the BFI website: http://old.bfi.org.uk/publications/ openingoureyes/downloads/Appendix-4-Cultural-ContributionSurvey-Data-SPSS-Format.zip.

A copy of the BFI dataset has been archived using the Enlighten research data repository managed by the University of Glasgow.

Enlighten: Opening our eyes: how film contributes to the culture of the UK - Appendix 4: Cultural consumption survey data. http:// dx.doi.org/10.5525/gla.researchdata.853 (Hanchard, 2019)

This project contains the following data:

- Cultural_Contribution.zip (Zip file containing BFI Opening our eyes survey data)

The University of Glasgow was granted full permission to store the dataset and to make fully it open access for public re-use without restriction. This permission was granted by the British Film Institute (BFI) Research and Statistics Manager on 13-Aug-2019.

Data are available under the terms of the Creative Commons Attribution 4.0 International license (CC-BY 4.0).

\section{Software availability}

$\mathrm{R}$ is a free statistical software available under GNU Affero general public license agreement (AGPL). R Studio, the graphical user interface used to operate $\mathrm{R}$ beyond its command-line interface is also freely available under a GNU AGP licence. The $\mathrm{R}$ packages used within this paper (poLCA version 1.4.1, pvclust version 2.0.0, glm version 3.6.1, and RcmndrMisc version 2.5.1) are extensions of $R$, and as such they are also openly available under R's GNU AGPL. R, R Studio, and all packages named above can be downloaded directly from the R project website: https://www.r-project.org/.

The $\mathrm{R}$ script used within the data analysis presented in this paper has been archived as a PDF file on the Enlighten research data repository managed by the University of Glasgow:

Enlighten: Beyond the Multiplex: $\mathrm{R}$ code for latent class analyses: https://dx.doi.org/10.5525/gla.researchdata.879 (Yates et al., 2019)

Data are available under the terms of the Creative Commons Attribution 4.0 International license (CC-BY 4.0).
Austin G: Introduction. In Austin G. (ed.) New uses of Bourdieu in Film Studies. New York: Berghahn Books, 2016; 1-12.

Reference Source

Bauman Z: Freedom. Milton Keynes: Open University Press. 1998.

Reference Source
Bauman Z: The Individualized Society. Cambridge: Polity. 2001. Reference Source

Bauman Z: Liquid Times: living in an age of uncertainty. Cambrdge: Polity. 2007. Reference Source

Beck U: From Industrial Society to the Risk Society: Questions of Survival, 
Social Structure and Ecological Enlightenment. Theory Cult Soc. 1992; 9(1): 97-123.

Publisher Full Text

Bennett T, Savage M, Bortolaia E, et al.: Culture, Class, Distinction. London: Routledge. 2009.

Publisher Full Text

Bourdieu P: Distinction: a social critique of the judgement of taste: conclusion. Abingdon: Routledge. 1984

Reference Source

Chan T, Goldthorpe J: Social Status and Cultural Consumption. In Chan, T. and Goldthorpe, J. (eds) Social Status and Cultural Consumption.. Cambridge: University of Cambridge Press, 2010; 1-27.

Publisher Full Text

Chan T, Goldthorpe J: Social stratification and cultural consumption: Music in England. Eur Sociol Rev. 2007a; 23(1): 1-19.

Publisher Full Text

Chan T, Goldthorpe J: Social stratification and cultural consumption: The visual arts in England. Poetics. 2007b; 35(2-3): 168-190.

Publisher Full Text

Chandler D: An Introduction to Genre Theory. Visual Memory. 1997; (Accessed: 26 September 2018).

Reference Source

DCMS: Taking Part Survey: England Adult Report, 2016/17. 2017; 1-35.

Reference Source

DiMaggio $\mathrm{P}$, Mukhtar T: Arts participation as cultural capital in the United States, 1982-2002: Signs of decline? Poetics. 2004; 32(2): 169-194. Publisher Full Text

Durgnat R: Films and Feelings. Cambridge, MA: MIT Press. 1971. Reference Source

Friedman S, Savage M, Hanquinet L, et al.: Cultural sociology and new forms of distinction. Poetics. 2015; 53: 1-8.

Publisher Full Text

Gans H: Popular culture and high culture: An analysis and evaluation oftaste. New York: Popular Books. 1999.

Reference Source

Giddens A: Modernity and Self-Identity: Self and Society in the Late Modern Age. Cambrdge: Polity. 1991.

Reference Source

Grixti J: Pop goes the canon: consumer culture and artistic value in screen adaptations of literary classics. Eur J Cult Stud. 2009; 12(4): 447-467. Publisher Full Text

Hanchard M: Opening our eyes: how film contributes to the culture of the UK - Appendix 4: Cultural consumption survey data. [Data Collection]. 2019. http://www.doi.org/10.5525/gla.researchdata.853

Hanquinet L: Visitors to modern and contemporary art museums: Towards a new sociology of "cultural profiles". Sociol Rev. 2013; 61(4): 790-813. Publisher Full Text

Hanquinet L, Roose H, Savage M: The Eyes of the Beholder: Aesthetic Preferences and the Remaking of Cultural Capital. Sociology. 2014; 48(1):
111-132.

Publisher Full Text

Hebdige D: Towards a Cartography of Taste 1935-1962. In Waites, B., Bennett, T., and Martin, G. (eds) Popular Culture: Past And Present. London: Open University Press, 1982; 194-219.

Reference Source

Higson A: The circulation of European films within Europe. Special issue of Comunicazioni sociali, 3(Special issue: The International Circulation of European Cinema in the Digital Age), (no date).

Publisher Full Text

Jones H: Statistical Report: Specialised Film in the UK Regions. Online. 2015; (Accessed: 8 August 2017).

Reference Source

Lamont M, Lareau A: Cultural Capital: Allusions, Gaps and Glissandos in Recent Theoretical Developments. Sociol Theor. 1988; 6(2): 153-168. Publisher Full Text

Le Roux B, Rouanet H, Savage M, et al.: Class and Cultural Division in the UK. Sociology. 2008; 42(6): 1049-1071.

Publisher Full Text

Northern Alliance and Ipsos MediaCT: Opening our eyes. Polity. 2011.

Reference Source

Peterson R, Simkus A: How Musical Tastes Mark Occupational Social Groups. In Lamont, M. and Fournier, M. (eds) Cultivating Differences: Symbolic Boundaries and the Making of Inequality. London: University of Chicago Press, 1992; 152-186. Reference Source

Savage M, Devine F, Cunningham N, et al:: A New Model of Social Class? Findings from the BBC's Great British Class Survey Experiment. Sociology. 2013; 47(2): 219-250.

Publisher Full Text

Savage M, Hanquinet L, Cunningham N, et al.: Emerging Cultural Capital in the City: Profiling London and Brussels. Int J Urban Reg Res. 2018; 42(1): 138-149. Publisher Full Text

The Warwick Commission: Enriching Britain: Culture, Creativity and Growth. Coventry: University of Warwick. 2015.

Reference Source

UK Govt: Creative industries: Sector Deal. London: Dept. for Business, Energy, and Industrial Strategy (BEIS) \& Dept. for Culture, Media, and Sports (DCMS)

2018.

Reference Source

Veblen T: The Theory of the Leisure Class. New York: Augustus M. Kelley. 1975 Reference Source

Warde A: Consumption, Food and Taste: Culinary Antinomies and Commodity Culture. London: Sage. 1997.

Publisher Full Text

Weber M: Economy and Society: An Outline of Interpretive Sociology. Berkeley and Los Angeles: University of California Press. 1968.

Reference Source

Yates S, Wessels B, Higson A, et al.: Beyond the Multiplex: R script for Latent Class Analyses. [Data Collection], 2019.

http://www.doi.org/10.5525/gla.researchdata.879 


\section{Open Peer Review}

\section{Current Peer Review Status:}

\section{Version 1}

Reviewer Report 27 November 2019

https://doi.org/10.21956/emeraldopenres.14265.r26550

(C) 2019 Kime A. This is an open access peer review report distributed under the terms of the Creative Commons Attribution License, which permits unrestricted use, distribution, and reproduction in any medium, provided the original work is properly cited.

\section{Anna Kime}

Birds Eye View Films, Sheffield, United Kingdom

The article is clear and well organised in taking the reader through the research and analysis undertaken. The data sources and how they impact on criteria are clearly outlined. The processes used to ensure data is analysed effectively are comprehensible. I was particularly reassured by the efforts taken to class and organise film genre and the use of sub-groups here. The conclusions from the available data are sound but the authors are right to point out research into wider influences is needed. I would add the proliferation of mass marketed films versus limited art house releases leads to greater awareness of and access to certain genres of film and that this should be included as a wider influence in future research.

Is the work clearly and accurately presented and does it cite the current literature? Yes

Is the study design appropriate and is the work technically sound? Yes

Are sufficient details of methods and analysis provided to allow replication by others? Yes

If applicable, is the statistical analysis and its interpretation appropriate? Yes

Are all the source data underlying the results available to ensure full reproducibility? Yes

Are the conclusions drawn adequately supported by the results? Yes

Is the argument information presented in such a way that it can be understood by a non- 


\section{academic audience?}

Yes

Does the piece present solutions to actual real world challenges?

Yes

Is real-world evidence provided to support any conclusions made?

Yes

\section{Could any solutions being offered be effectively implemented in practice?} Yes

Competing Interests: No competing interests were disclosed.

Reviewer Expertise: Cultural film exhibition

I confirm that I have read this submission and believe that I have an appropriate level of expertise to confirm that it is of an acceptable scientific standard.

Reviewer Report 19 November 2019

https://doi.org/10.21956/emeraldopenres.14265.r26548

(c) 2019 Muzareba A. This is an open access peer review report distributed under the terms of the Creative Commons Attribution License, which permits unrestricted use, distribution, and reproduction in any medium, provided the original work is properly cited.

\section{Abureza M. Muzareba}

Department of Marketing, University of Dhaka, Dhaka, Bangladesh

The work is clearly and accurately presented. I found a consistent flow of logic supported by current and important literature. Particularly the works of Austin is appropriately referred. However, authors could have enhanced the interdisciplinarity aspects of this work by referring to Michael R Solomon's book titled 'Consumer behaviour: A European Perspective'.

The study design has rigor. It included a data source of considerable size which also came from authentic source. The work looks technically sound to me. The authors have done justice to the appropriate use of proper statistical tool given the nature of data set they have used.

Methods and analysis are adequately discussed for any researcher to benefit from. I believe a lot of researchers will refer to this paper specifically for the methods and approach to data analysis.

Statistical analyses and their interpretation are the major strength of this paper. While majority of the works in this category are done following qualitative approach, this work stands out with its innovative approach to make sense of data, particularly when the data size is large and predominantly categorical. 
All the sources of the data used for this work are available within the article. I am confident that any researcher can reproduce the results using the same data set.

Conclusions clearly reflect the results produced by the data set.

Is the work clearly and accurately presented and does it cite the current literature?

Yes

Is the study design appropriate and is the work technically sound?

Yes

Are sufficient details of methods and analysis provided to allow replication by others? Yes

If applicable, is the statistical analysis and its interpretation appropriate? Yes

Are all the source data underlying the results available to ensure full reproducibility? Yes

Are the conclusions drawn adequately supported by the results? Yes

Is the argument information presented in such a way that it can be understood by a nonacademic audience?

Yes

Does the piece present solutions to actual real world challenges?

Yes

Is real-world evidence provided to support any conclusions made?

Yes

Could any solutions being offered be effectively implemented in practice?

Yes

Competing Interests: No competing interests were disclosed.

Reviewer Expertise: Digital Sociology, Digital Anthropology, Consumer Behaviour, E-Marketing, ICT4D

I confirm that I have read this submission and believe that I have an appropriate level of expertise to confirm that it is of an acceptable scientific standard. 